\title{
The Rise and Fall of Frequency and Imageability: Noun and Verb Production in Semantic Dementia
}

\author{
Helen Bird,* Matthew A. Lambon Ralph,* Karalyn Patterson,* \\ and John R. Hodges*, $\dagger$
}
*MRC Cognition and Brain Sciences Unit, Cambridge, United Kingdom; and University Neurology Unit, Addenbrooke's Hospital, Cambridge, United Kingdom

\begin{abstract}
This study examines the impact of progressive degeneration of conceptual knowledge on the content words used in connected speech elicited using the Cookie Theft picture description (Goodglass \& Kaplan, 1983). We began with an analysis of control subjects' descriptions with regard to word types and their frequency and imageability. Because the impairment of conceptual knowledge in semantic dementia is graded by concept familiarity, we created a model of a standardized normal Cookie Theft description that was then progressively degraded by the systematic removal of lower bands of word frequency. We drew two main predictions from this model: reduced availability of the lower bands of word frequency should result in (a) an apparent deficit for noun retrieval in relation to verb retrieval and (b) an apparent reverse imageability effect. Results from a longitudinal study, in which three patients with semantic dementia each described the Cookie Theft picture on three occasions during the progression of their disease, confirmed these predictions. An additional cross-sectional analysis, adding narratives from a larger number of cases, demonstrated that the decline in ability to produce suitable words for the picture description is closely related to the extent of semantic impairment as measured in tests of word comprehension and production. Both verbs and nouns are affected by the degradation of semantic memory; the fact that the impairment to noun production is manifested earlier and more catastrophically may be attributed to the relatively lower frequency of these terms. ( 2000 Academic Press
\end{abstract}

Key Words: semantic dementia; progressive aphasia; nouns; verbs; frequency; imageability; narrative; spontaneous speech; Cookie Theft; picture description.

The authors thank the patients and the members of the MRC Cognition and Brain Sciences Unit Volunteer Panel for their participation in this study. We are also grateful to two anonymous reviewers for their helpful comments on an earlier version of this paper. The research was in part funded by an EPS study visit award to the first author and by an NIH grant to J. L. McClelland and K. Patterson.

Address correspondence and reprint requests to Helen Bird, MRC Cognition and Brain Sciences Unit, 15 Chaucer Road, Cambridge, CB2 2EF UK. E-mail: Helen.Bird@mrc-cbu. cam.ac.uk. 


\section{INTRODUCTION}

How does degraded conceptual knowledge impact natural speech production? The documented deterioration of semantic memory during the course of progressive fluent aphasia (semantic dementia) clearly disrupts the ability to communicate successfully, but how exactly is this manifested in speech, and what measures can we use to characterize this impairment? Single word assessments, although informative with regard to particular linguistic abilities, are not representative of speech and language as it is normally used, that is, in connected speech. Analyses of more naturalistic speech samples therefore need to be used in aphasia research, to complement other more constrained tests of word retrieval, and to assess whether the findings of single word tasks extend to spontaneous speech.

Saffran, Berndt, and Schwartz (1989) asked aphasic patients to tell the story of Cinderella and developed a procedure for the quantitative analysis of the speech samples collected. Ratios between the numbers of words of different types were examined, as well as numerous other measures of the use of grammatical markers. This proved a reliable tool to describe agrammatic speech and its heterogeneity in terms of the dissociation between free and bound morphology. More recent analyses (Rochon, Saffran, Berndt, \& Schwartz, 1998) of a larger data set confirmed the reliability of the original technique. The "Cinderella" method has been used to compare the speech of individual patients and to assess change over time during spontaneous recovery and during a course of treatment (Bird \& Franklin, 1996; Breedin, Saffran, \& Schwartz, 1998; Hesketh \& Bishop, 1996; Marshall, Pring, \& Chiat, 1998).

Picture description provides another constrained method of eliciting connected speech, although it is worth noting that it is not necessarily representative of other, more natural, forms of speech: one might expect, for example, a higher proportion of concrete nouns to be employed compared with conversation and storytelling. The picture description method does, however, have the advantage of placing constraints on production within the context of connected speech. Analysis of picture description has been employed in the assessment of language abilities in individuals with dementia of the Alzheimer's type (DAT: Croisile, Ska, Brabant, Duchene, Lepage, Aimard, \& Trillet, 1996; Giles, Patterson, \& Hodges, 1996; Tomoeda, Bayles, Trosset, Azuma, \& McGeagh, 1996) and to differentiate DAT from multiinfarct dementia (Mendez \& Ashlamendez 1991). This research has typically focused upon measures such as informational content and grammatical complexity. Two of the studies (Croisile et al. 1996; Giles et al. 1996) used the Cookie Theft picture description from the Boston Diagnostic Aphasia Examination (BDAE; Goodglass \& Kaplan, 1983). As Giles et al. comment, the Cookie Theft picture provides a clear focus, and its contents are domestic and hence familiar for all subjects. The same picture stimulus was used by Ardila and 
Roselli (1996), who ascertained that ratios of different word types were relatively uniform across age, sex, and level of education in normal speakers. The only differences they found were that more highly educated subjects produced more words in total and that increasing age was associated with reduced production for the male subjects.

The research described here brings these methods to the study of fluent progressive aphasia or semantic dementia (Hodges, Patterson, Oxbury, \& Funnell, 1992; Snowden, Goulding, \& Neary, 1989). Individuals with this disorder present with fluent but anomic speech and an accompanying comprehension deficit (Hodges, Graham, \& Patterson, 1995). As their semantic memory deteriorates, they become increasingly anomic and their spontaneous speech more "empty." Semantic dementia is the temporal variant of frontotemporal dementia. MRI structural scans and voxel-based morphometry indicate that the disease affects inferior and lateral aspects of the temporal lobes bilaterally though asymmetrically, often with more severe atrophy on the left (Hodges et al., 1992; Mummery, Patterson, Wise, Price, \& Hodges, 1999). These patients are characterized by the preservation of general cognitive abilities (at least until much later stages of the disease), while the aspects of language and other cognitive function that specifically depend on semantic knowledge become severely impaired. The aim of this study was to investigate the impact of progressive semantic impairment on speech production in semantic dementia (SD), as revealed by connected speech samples elicited by picture description. This was achieved in the first instance by the analysis of speech in terms of the numbers of different words produced in various classes and the relationships between these counts, for example, the relative proportions of content to function words and of nouns to verbs.

Saffran et al. (1989) demonstrated that the speech of agrammatic patients had a significantly lower proportion of closed class or function words than found in normal control subjects. By contrast, two fluent anomic patients studied by Bird and Franklin (1996) produced a slightly higher than normal proportion of function words. Patients with severe SD, who have fluent but very anomic speech, might be expected to exhibit an even more marked increase in the proportion of function words in relation to the total narrative. The ratio of nouns to verbs has been the focus of many studies seeking to capture the qualities of different aphasia types. Jonkers and Bastiaanse (1998) and Bastiaanse and Jonkers (1998) compared the ratio of verbs to total words produced in the spontaneous speech of aphasic patients for whom confrontation naming of verbs was particularly poor. These authors found no consistent correlation between performance on single word verb naming and the production of verbs in connected speech, highlighting a limitation in the use of spontaneous speech analysis to demonstrate specific deficits. Reports of poorer ability to retrieve verbs compared with nouns in single word tasks are prevalent in the aphasia literature, not only in nonfluent agrammatic aphasia (Zingeser \& Berndt, 1990), but also in other aphasic 
disorders (e.g., Berndt, Haendiges, Mitchum, \& Sandson, 1997). Conversely, case studies describing patients whose retrieval of verbs is better than nouns are relatively rare (Berndt et al. 1997; Marshall, Chiat, Robson, \& Pring, 1996).

Most research to date on word finding in SD has focused on concrete nouns, using mainly picture naming and category fluency tasks, although the study by Breedin, Saffran, and Coslett (1994) describing patient DM is one exception in its examination of verbs as well. DM performed marginally better at verbs than nouns in naming to definition and on a synonym judgment task. It is possible, however, that this word class difference was a byproduct of the patient's reverse concreteness effect: DM, like two other reported SD patients (Cipolotti \& Warrington, 1995; Warrington, 1975), showed an advantage for abstract over concrete words, and, as we will see later, many commonly used verbs are more abstract than nouns.

Daniele, Silveri, Giustolisi, and Gainotti (1993) and Daniele, Giustolisi, Silveri, Colosimo, and Gainotti (1994) also described a patient, GP, with progressive atrophy of the left temporal lobe, who performed better with verbs than nouns in both naming and comprehension, with items controlled for frequency and length. On an oral confrontation naming task drawn from a preliminary version of the Battery for the Analysis of Aphasic Deficits (Miceli, Laudanna, \& Burani, 1991), GP scored 2/30 for nouns and 13/36 for verbs, a significant difference in favor of verbs. On a subsequent testing session, when comprehension was also assessed, the difference in naming success between nouns and verbs was no longer significant (nouns 1/24, verbs 5/29), but GP was significantly worse at nouns than verbs in the spoken word-picture matching test and in lexical decision (both written and spoken).

The general impression of the speech of SD patients is that it is fluent and on the whole grammatically acceptable. To produce a well-formed sentence it is necessary to include a verb, but nouns can be replaced by pronouns without damaging the structural integrity of the sentence. We can therefore assume that these individuals are able to retrieve a sufficient number of verbs to produce sentences, but this does not necessarily indicate that verbs are spared relative to nouns. If the patients' deficits are due to generalized semantic damage, and provided one does not assume that separate semantic systems exist for different word classes, then it is likely that all word classes should be impaired. If verbs did turn out to be spared relative to nouns, then one would need to look at the factors predicting word retrieval and how these relate to the different characteristics of the grammatical categories. Lambon Ralph, Graham, Ellis, and Hodges (1998) demonstrated that the factors which consistently affect picture naming in SD are object familiarity, frequency, and age of acquisition of concept names. As verbs tend to be, on average, of higher frequency than nouns, a generalized frequency effect in patients would predict that nouns should be more adversely affected in any task, including spontaneous speech, where there is no control for such variables. 
Bird and Franklin (1996) used the Cinderella story to examine the specific nouns and verbs produced by aphasic patients and normal speakers and to quantify these in terms of their frequency of occurrence, length, and imageability. The majority of studies which claim to find significant deficits specific to word class have neglected the latter variable. It can be assumed that all words used in naming tasks are (necessarily) highly imageable, but this does not guarantee that the nouns and verbs are equally imageable. Imageability ratings for nouns and verbs (used in this study and described in more detail later) indicate that most pictureable verbs receive lower ratings of imageability than most pictureable nouns, rendering control for this variable in noun and verb naming infeasible. The use of a connected speech sample does not provide any kind of control of these variables; but examination of the word frequency and imageability of lexical items produced by both patients and normal controls may shed some light on how these factors interact with grammatical class.

The remainder of the paper is divided into three sections. We begin with the analysis of data from normal speakers to build a picture of a "normal" Cookie Theft picture description with regard to the ratios of different word classes and the relationship between these and the psycholinguistic variables of interest. We then introduce data from patients with semantic dementia, in the context of describing the expected impact on successive picture descriptions of a decreasing ability to produce words of low frequency. Our longitudinal picture descriptions come from three patients at different time points in the evolution of their disease, and we compare these results with the predicted data. Finally we present a cross-sectional study incorporating additional Cookie Theft descriptions collected from other SD patients. Analyses of these cross-sectional data are compared with performance in other tasks of both production and comprehension.

\section{CONTROL DATA AND MODELING THE DECLINE OF CONNECTED SPEECH IN THE COOKIE THEFT PICTURE DESCRIPTION}

\section{Subjects}

Twenty normal control subjects (15 female and 5 male), who were members of the MRC Cognition and Brain Sciences Unit volunteer panel, were matched approximately to the patients in the longitudinal study for age and educational level. The mean age of the controls was 67.5 years (range 5775), and the mean education was 10.65 years (range 9-16).

\section{Method}

Each subject described the Boston Cookie Theft picture (Goodglass \& Kaplan, 1983) once. In all cases the instructions were "tell me everything you see going on in this picture.' The narratives were tape recorded and then transcribed and timed (with experimenter talk timed and subtracted). The total words were counted (removing expressions of hesitation such as $o h$, er, and um and counting contractions such as they'd or hasn't as two separate words), 
and the total words per minute were calculated. The words were separated into content and function words (as per Saffran et al. 1989) and the proportion of content words was calculated. Instances of nouns and main verbs (excluding auxiliaries and modals) by token and by type were counted. The ratios of nouns to verbs (by token and by type) and of nouns and verbs (together and separately by type) to total words were calculated.

Nouns and verbs were then entered into a frequency analysis: the log frequency per million words by lemma (spoken and written forms combined) for each word was extracted from the Celex Lexical Database (Baayen, Piepenbrock, \& van Rijn, 1993), and the mean frequency of the words produced was calculated. The range of word frequency per million words was also divided into eight bands according to a log scale, and the number of items (by type) produced within each of these bands was counted, providing a distribution pattern across the frequency bands.

Nouns and verbs were also analyzed for their imageability. There are many homonyms in English that can be used as nouns as well as verbs, and this can make imageability ratings ambiguous. If, for example, we require a rating for the verb whistle, and we simply include whistle on a list, we have no way of knowing whether raters considered the object, the action, or some combination of both. It is reasonable to assume that in many cases the noun and the verb usage of a word form might receive different ratings, due to differences in their semantic representations. Published imageability ratings are therefore not suitable when items are ambiguous as to word class. In our study, imageability ratings from the MRC Psycholinguistic Database (Medical Research Council, 1997) were used only for items that were unambiguous. An additional set of imageability ratings for a large selection of words (including many verbs) have been collected from 75 normal subjects (Bird, unpublished data), specifying ambiguous items by adding to for verbs (e.g., to whistle) and $a$ or $a$ for nouns (e.g., $a$ whistle) and giving subjects clear instructions to consider the meaning of the word which was appropriate for its grammatical class. Imageability ratings from these two sources were available for more than $90 \%$ of the nouns and verbs produced in the Cookie Theft descriptions. The imageability scale was also divided into bands and these were incorporated with the frequency data to show the number of nouns and verbs produced within these two dimensions.

A remarkably illustrative example of simulated connected speech typical of fluent anomic aphasia was created by Marshall (1977), by using only the 100 most frequent words of English. Word frequency is one of the factors that consistently affects picture naming in SD, so one might expect that the same would apply to picture description. We employed a similar method to that of Marshall (1977) to illustrate how the unavailability of low frequency words might affect a Cookie Theft description. A "normal model" Cookie Theft description was written based on the content of most control subjects' narratives. The aim was to include all the salient points and the kind of vocabulary that is normally used when describing the picture and then to show how graded inaccessibility of the required vocabulary might impair performance on the task. The initial normal description was rewritten, therefore, while attempting to convey approximately the same information, but without using any words from the lower frequency bands.

Frequency bands were removed systematically and successively, beginning with bands representing $\log$ frequencies $0-0.5$ and $0.5-1.0$ (the equivalent of being able to produce only items which occur more than 10 times per million words) and ending with only the two highest bands available (a restriction to words which occur at least 1000 times per million). By removing one band at a time, six versions of the narrative were written. These are shown in the Appendix: words in bold show where changes to the original text had to be made to accommodate the reduction in vocabulary. Hesitations were added for realism, but these were never entered into any analyses. Comments such as "I can't remember the word" were also included, because these are observed so often in individuals with progressive fluent aphasia. In the analyses using these "model" Cookie Thefts, such comments were included, though exclusion of these items made no difference to any of the results.

Three time periods of the modeled progressively aphasic Cookie Theft description were selected for analysis. These were the first "normal" version, with all frequency bands intact, 
and those with only words of log frequency greater than 2.0 (100 occurrences per million) or 3.0 (1000 occurrence per million), referred to as "normal," " $2.0+$," and " $3.0+$." It was hoped that the latter two model descriptions would emulate the performance of patients suffering moderate and severe impairments, respectively. The constructed narratives were analyzed with respect to counts of content and function words, as well as nouns and main verbs, and these scores were compared with those of true normal control subjects. The mean frequency and imageability of the words included were also compared.

\section{Results}

Table 1 shows the profile of normal control scores and the three versions of the "model" Cookie Theft. There is considerable variation within the control subjects in the total length of narrative and in ratios of nouns to verbs both by token and by type. The "normal" model is well within the normal ranges on all measures. The ratios of both nouns and verbs by type to total narrative words (the final columns in Table 1) are more consistent across control subjects, and it is this measure which exhibits the earliest effect of reduced vocabulary in the model Cookie Thefts. When only bands over log frequency 2.0 are available, the ratio of nouns to total words is reduced to the lower limit of the normal range, but we see no reduction in the number of verbs used, nor any change in the content/function ratio. In version 3.0+ the ratios of nouns to total words, nouns to verbs, and content to function words are all well below the normal ranges. The type/total ratio for verbs is reduced, but still does not fall below the normal range. The removal of frequency bands meant in practice that many words used in the original narrative had to be substituted by items of higher frequency but of the same class. Such within-class substitution would not be revealed in these analyses, demonstrating the limitations of using ratios alone to detect impairment. Only later in the progression, when there is no alternative but to substitute pronouns for nouns and perhaps verb phrases for single verbs, do we see differences in the ratios of nouns to verbs and content to function words. This gives the impression of a deficit that affects nouns to a much greater extent than verbs.

The numbers of nouns and verbs (by type) produced by the 20 control subjects in each band of frequency and imageability are shown in Figs. 1a and $1 \mathrm{~b}$, respectively. The first graph demonstrates that control subjects produce a large number of nouns in the middle bands between log frequencies 1.0 and 3.0, with a few nouns in the lowest frequency band and none in the highest. Verbs are spread more evenly over the frequency bands, but notably none are in the lowest band. The two highest frequency bands contain $31 \%$ of all the verbs produced by control subjects, but only $4 \%$ of their nouns. A complementary contrast occurs for imageability. That is, most of the nouns appear in the two highest bands of imageability (note that this is a picture description), and only 1 noun (sort) of the 392 noun types produced by the 20 controls occupies the lowest imageability band. The verbs are again well spread across the bands, but only 1 (touch) appears in the highest band, of 
BIRD ET AL.

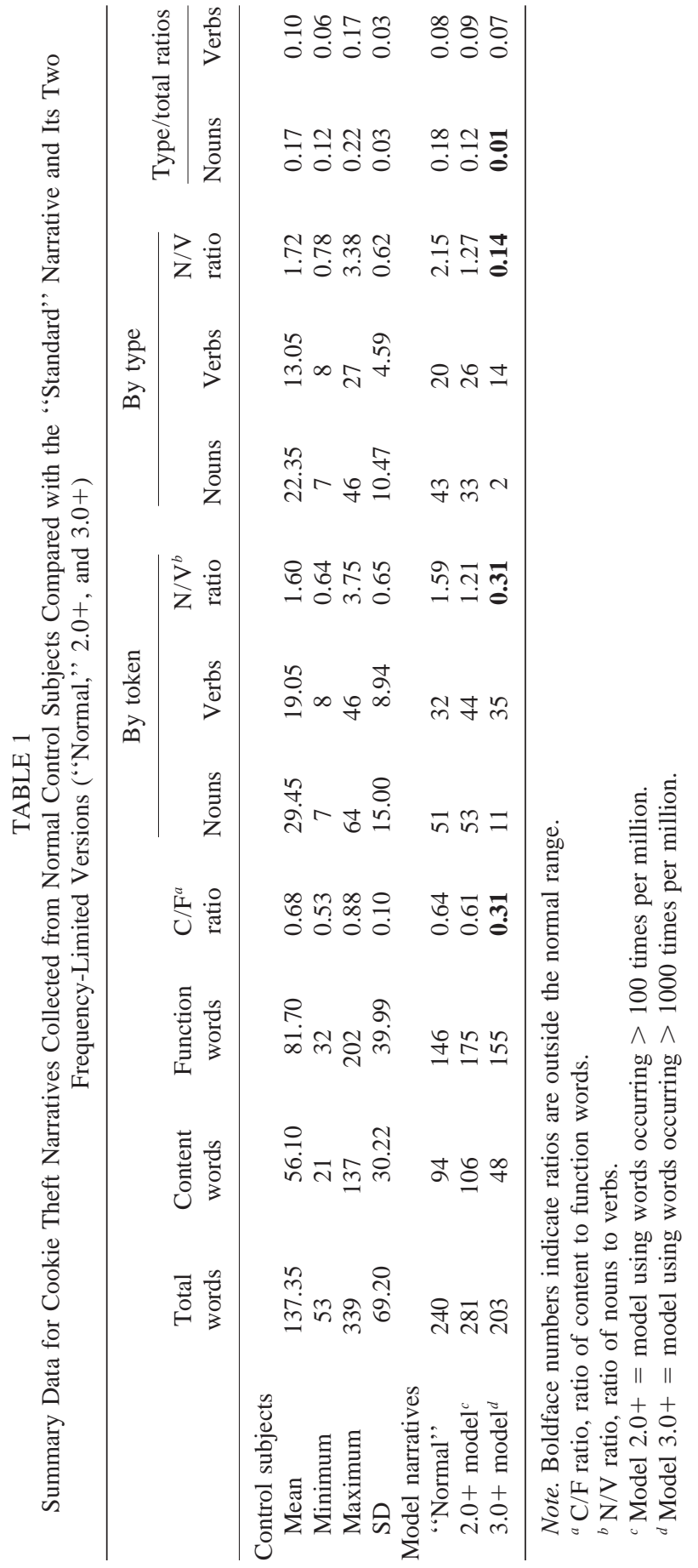




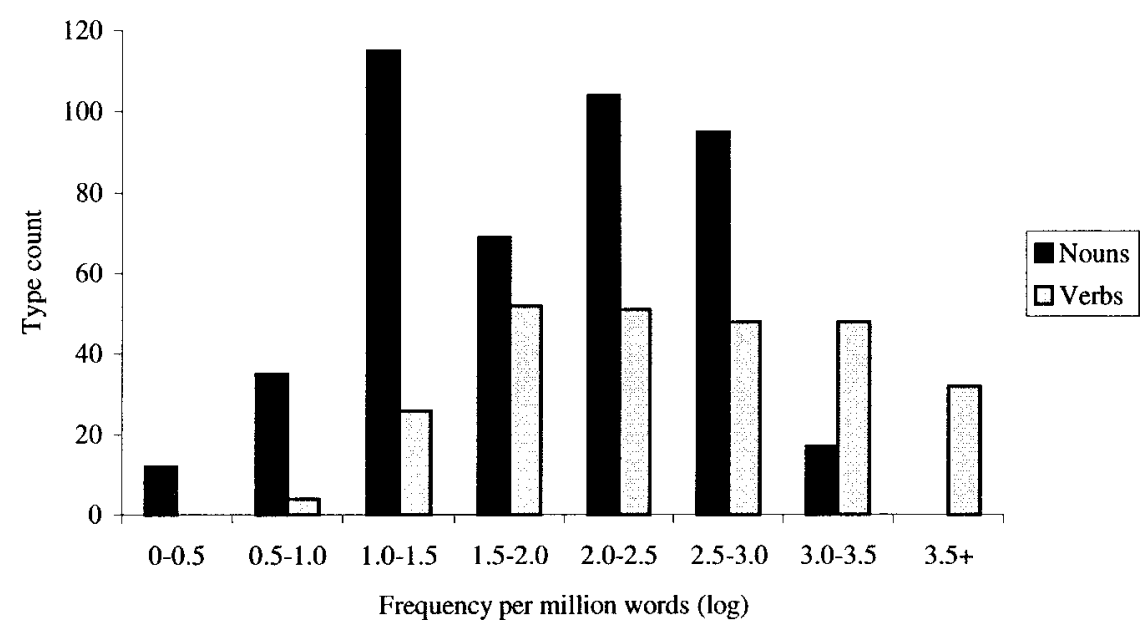

a

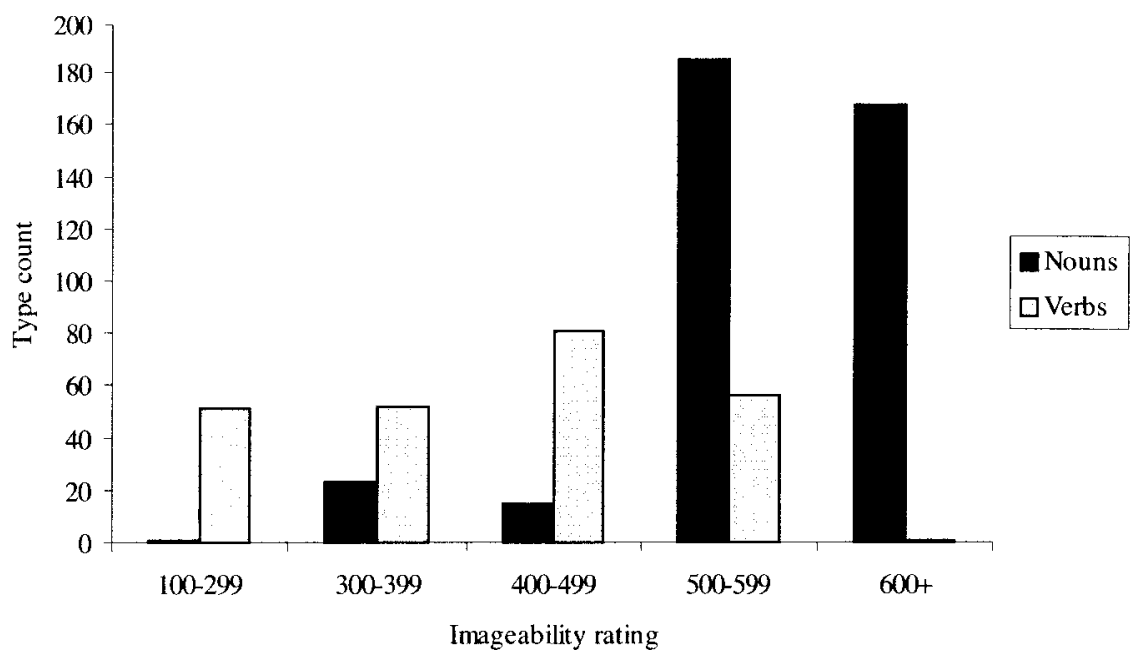

b

FIG. 1. (a) Numbers of nouns and verbs produced by control subjects in each frequency band. (b) Numbers of nouns and verbs produced by control subjects in each imageability band.

the 241 produced by control subjects. The lower three imageability bands contain $77 \%$ of the verbs, but only $10 \%$ of the nouns.

The contour graphs in Fig. 2 show the control subjects' distribution of words across frequency and imageability simultaneously. Nouns represent chiefly a horizontal range of highly imageable words with two peaks at log frequencies 1.0-1.5 (words such as stool and sink) and 2.0-2.5 (e.g., mother and water). Verbs occupy the diagonal stretch from the medium values of the two variables (e.g., reach and pass) toward the high frequency, low im- 

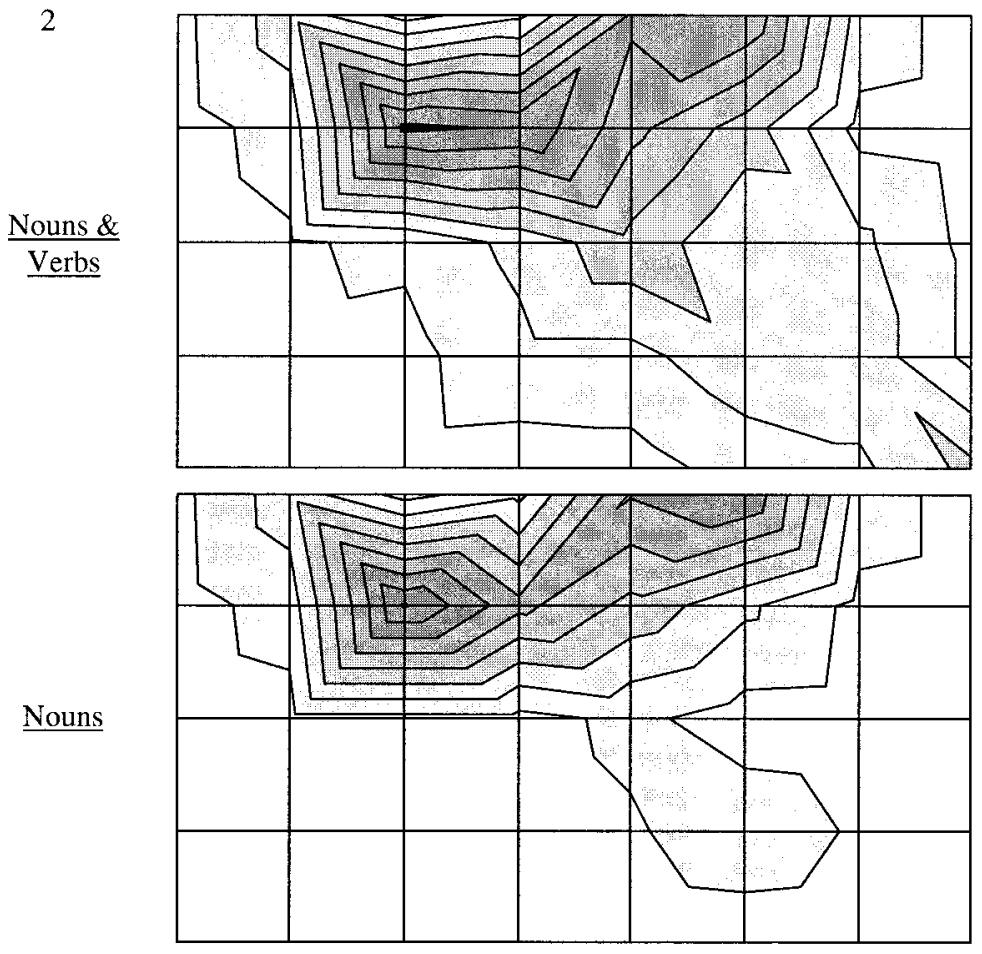

$600+$

$500-599$

$400-499$

클

$300-399$

$100-299$

Verbs
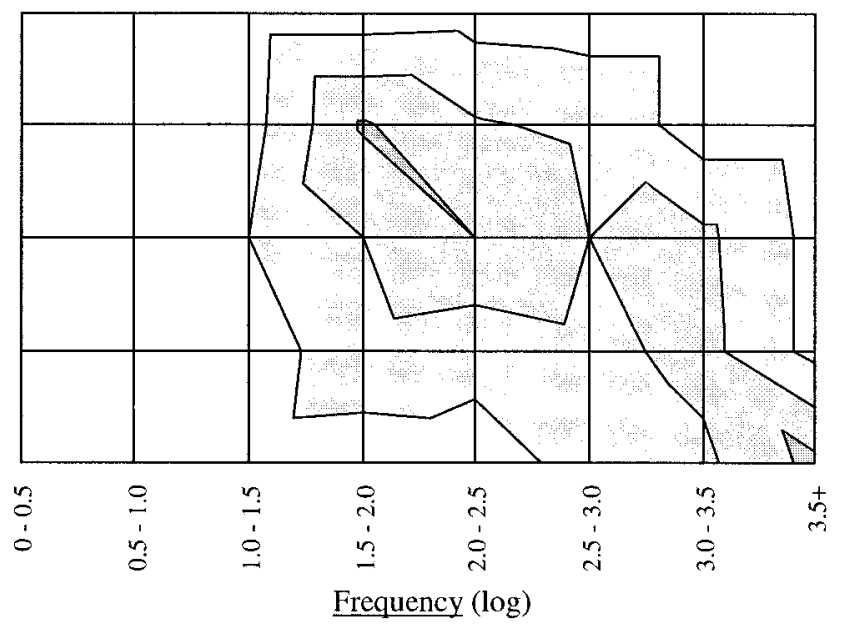

\section{LEGEND}

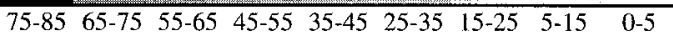

Number of words (type count)

FIG. 2. Contour distributions across frequency and imageability of nouns and verbs produced by control subjects. 
ageability corner (e.g., take and want). There is relatively little overlap between the two word classes on these dimensions. The kinds of items in the overlap area (frequency 1.5-2.5, imageability 400-500) are medium-specific nouns (e.g., top and household) but highly specific action verbs (e.g., fall and climb). If bands of frequency lower than 2.0 were not available due to the progression of aphasia in semantic dementia, the full range of verbs should remain available until late in the disease. The necessary specific nouns normally recruited for describing this picture (nouns such as stool and cupboard), however, are all in the lower frequency bands; thus if frequency were a major factor governing availability of lexical items for speech production in $\mathrm{SD}$, these nouns should be vulnerable early in the course of the disease.

The contour graphs in Fig. 3 show the distribution across both frequency and imageability of words used in the three model versions. If frequency bands $0-3.0$ are removed from the graph, the words cluster in the lower righthand corner, which represents high frequency and low imageability items. Importantly, almost all these words are verbs. Only two nouns were available in the $3.0+$ version: child and thing. In contrast, many verbs were still available: be, come, do, get, give, go, have, know, look, make, see, tell, think, and want. This goes some way to explaining why the number of verbs in relation to total words remains within the normal range and why the noun to verb ratio is much reduced in version $3.0+$.

The mean frequency and imageability of the words produced in the three model Cookie Theft narratives as well as those from the normal control subjects (shown in Table 2) were entered into one-way ANOVAs (nouns and verbs collapsed). Naturally, the effect of frequency was significant $[F(3$, $834)=17.50, p<.001]$. According to Tukey's HSD there was no difference in frequency between the "normal" model and the actual normal controls, but there were significant differences between all three versions of the model narratives and between true controls and the two frequency-limited narratives. The effect of imageability was also significant $[F(3,756)=9.71, p<$ .001]. Again, there was no difference between the normal model and the actual control subjects. Here the significant differences lay between the normal and 3.0+ $(p<.001)$ and the $2.0+$ and $3.0+$ versions $(p=.001)$ and between control subjects and version $3.0+(p<.001)$. A significant reduction in imageability is revealed, therefore, only when words of 1000 per million or fewer are excluded from the narratives.

When the frequencies of the nouns and verbs were entered separately into one-way ANOVAs, both showed significant differences between the model versions [nouns, $F(2,68)=12.03, p<.001$; verbs, $F(2,56)=5.76, p=$ $.005]$. Posthoc tests revealed that the mean frequency of the nouns was significantly higher than normal for both versions $2.0+$, and $3.0+$, but the difference between these two versions did not reach significance. In contrast, the significant difference occurred for verbs between versions $2.0+$ and $3.0+$ : the reduced use of low frequency words does not lead to a significantly 

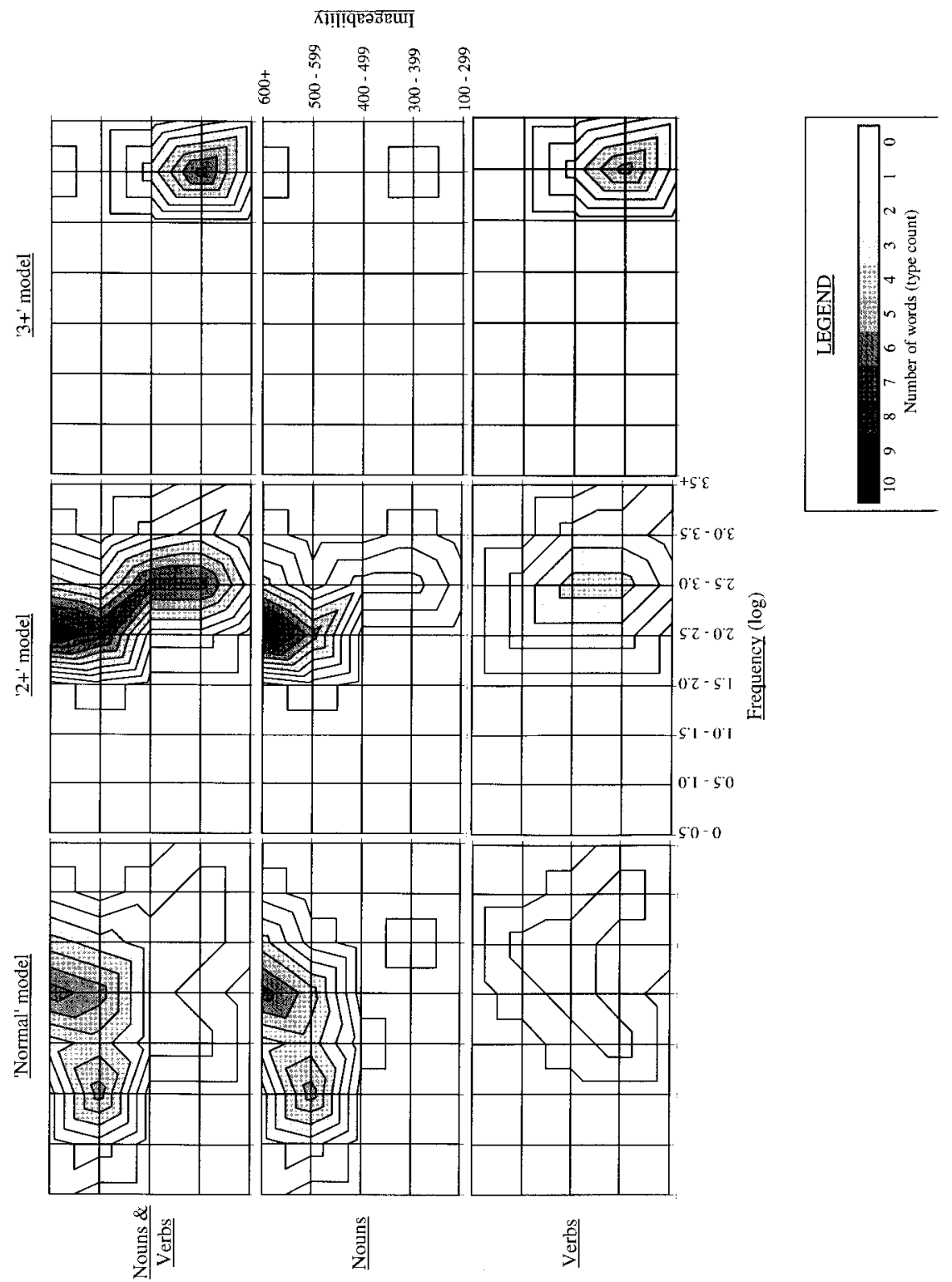

ن 
TABLE 2

Mean Frequency and Imageability of Nouns and Verbs Produced by Control Subjects and

Contained in the "Standard" Narrative and Its Two Frequency-Limited Versions (Versions "Normal," 2.0+, and 3.0+)

\begin{tabular}{lcccc}
\hline & $\begin{array}{c}\text { Control } \\
\text { subjects }\end{array}$ & $\begin{array}{c}\text { "Normal" } \\
\text { model }\end{array}$ & $2.0+$ model & $3.0+$ model \\
\hline Mean frequency & & & & \\
$\quad$ Nouns and verbs & 2.12 & 2.20 & 2.63 & 3.39 \\
$\quad$ Nouns & 1.84 & 1.92 & 2.42 & 3.02 \\
$\quad$ Verbs & 2.60 & 2.76 & 2.89 & 3.44 \\
Mean imageability & & 522 & 479 & 489 \\
$\quad$ Nouns and verbs & 510 & 582 & 548 & 348 \\
$\quad$ Nouns & 569 & 402 & 397 & \\
$\quad$ Verbs & 414 & & & \\
\hline
\end{tabular}

higher mean than normal for this word class when bands 0-2.0 are removed. This is because the verbs which are normally used (as seen in Fig. 1) cluster around the higher frequency bands, so they are scarcely affected by the "loss" of lower frequency bands. The opposite is true for nouns. This is important, because it mirrors what we have already seen in the analysis of the ratios: the loss of low frequency items has an earlier and more catastrophic effect for nouns, while verbs are relatively spared.

\section{Discussion}

We have demonstrated first that the "normal" model Cookie Theft description is representative of normal subjects. Second, the results from the impoverished narratives suggest that unavailability of all but the highest frequency items results in the production of words of abnormally low imageability, almost all of which are verbs. That is, by analyzing the distribution of frequencies that different word classes occupy in a typical Cookie Theft narrative, we have established that a simple reduction in the availability of lower frequency words in connected speech can lead to an apparent specific word class deficit. These results also suggest that a particularly severe impairment may result in an apparent reverse imageability effect, because very high frequency words tend to be of lower imageability. In the next section we demonstrate that the narratives of real patients suffering from a progressive deterioration of semantic memory reveal a similar pattern during the course of their disease.

\section{LONGITUDINAL STUDY}

\section{Subjects}

Three subjects (two female and one male) with semantic dementia (SC, FM, and AM) took part in the longitudinal study. SC has been previously 
reported by N. Graham, Patterson, and Hodges (1997b); FM by Hodges et al. (1992), K. Graham et al. (1995), and Tyler, Moss, Patterson, and Hodges (1997); and AM by Hodges and Patterson (1996), Knott, Patterson, and Hodges (1997), K. Graham, Lambon Ralph, and Hodges (1997a), K. Graham and Hodges (1997), and Tyler and Moss (1998). The mean age of these three cases across testing sessions was 65.0 years (range $55-76$ ), and their mean education was 12.3 years (range 10-16). $T$ tests showed no difference between the patient and control groups on age or educational level.

\section{Method}

Each SD patient described the Boston Cookie Theft picture (Goodglass \& Kaplan, 1983) at three different time periods during the longitudinal study. The chronology of the time periods varied across patients. The dates and results of several neuropsychological tests are shown in Table 3 (for more detailed descriptions of these measures see Hodges \& Patterson, 1995). Analyses of the patients' narratives were conducted in exactly the same manner as described above, and the results compared with those of the normal controls. Comparisons were also conducted within each SD subject longitudinally. The individual nouns and verbs produced by each SD subject were examined for consistency across the three narratives. Of particular interest were the items produced in the first version that did not appear later, compared with items which appeared in all three versions, and those which emerged on only the second and/ or third testing period.

It is important to note first that these three patients were at different stages of severity, with $\mathrm{SC}$ at an earlier stage than the other two. This is clear from the test scores shown in Table 3 . The assessments also covered very different time windows, with the dates of the Cookie Theft narratives of SC and AM spanning about 2.5 years each, while FM's picture descriptions were collected over a 6-year period.

\section{Results}

The narratives produced by these three patients with semantic dementia did not differ from normal control subjects' in the number of words per minute. Table 4 shows the counts and ratios of content and function words and nouns and verbs. The two subjects with more severe deterioration in semantic knowledge (FM and AM) had a lower ratio of content to function words than normal controls (see Table 1). The ratios of nouns and verbs to total narrative words also reflect this pattern, but only the more severe deficits result in a lower than normal ratio of verbs to total words (SC2 and 3, FM3, and $\mathrm{AM})$.

Figure 4 presents the mean frequency of nouns and verbs (by type) produced in the patients' Cookie Thefts. The frequency of content words produced increased over time consistently for both FM and AM. This applies to nouns and verbs separately but the number of items in the individual word classes is too small to reach significance. For SC, the mean frequency of both nouns and verbs produced decreased slightly in the second period and then increased again at the third testing period. Word frequencies were entered into a univariate ANOVA (dependent variable = frequency, fixed vari- 


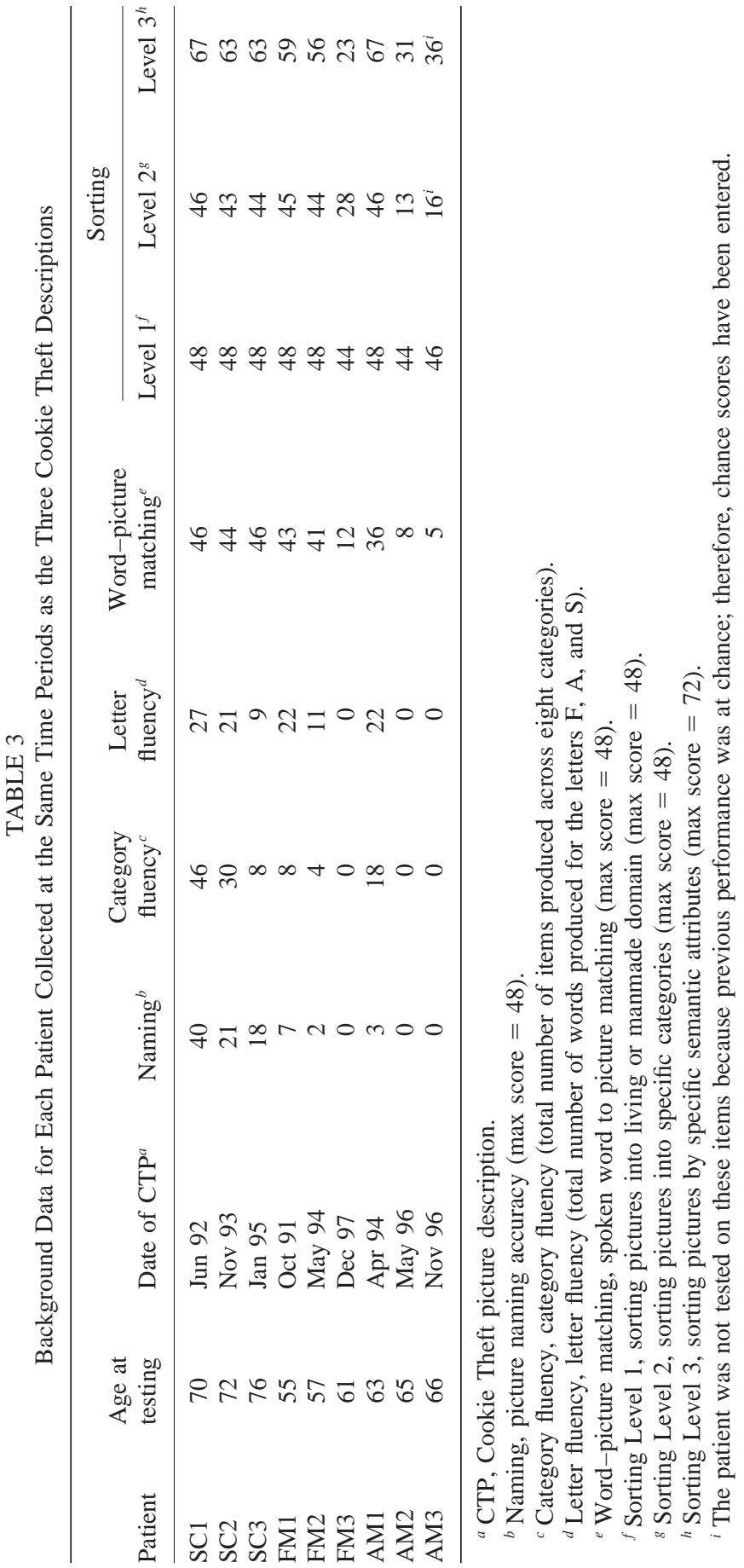


兽|

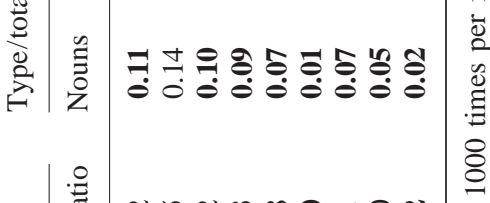

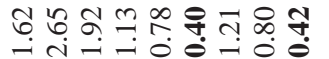

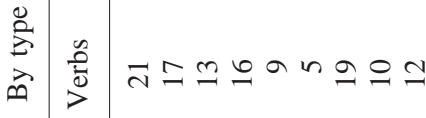

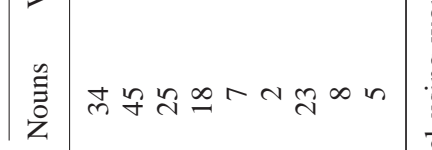

(2)

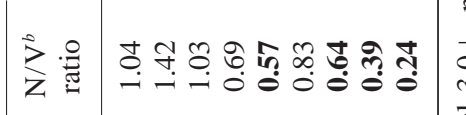

串

宽

皇

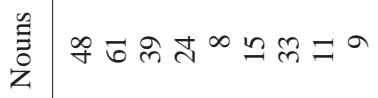

苞

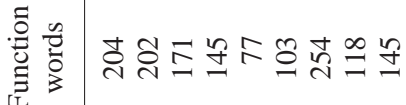

एี

$\stackrel{0}{\Xi}$

튼

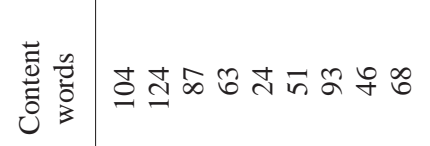

焉总

일

吾

○ 3

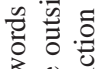

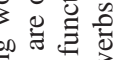

至.

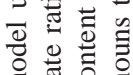

ฮु ठㅇ

+ 突业

닐

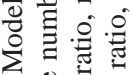

莞 


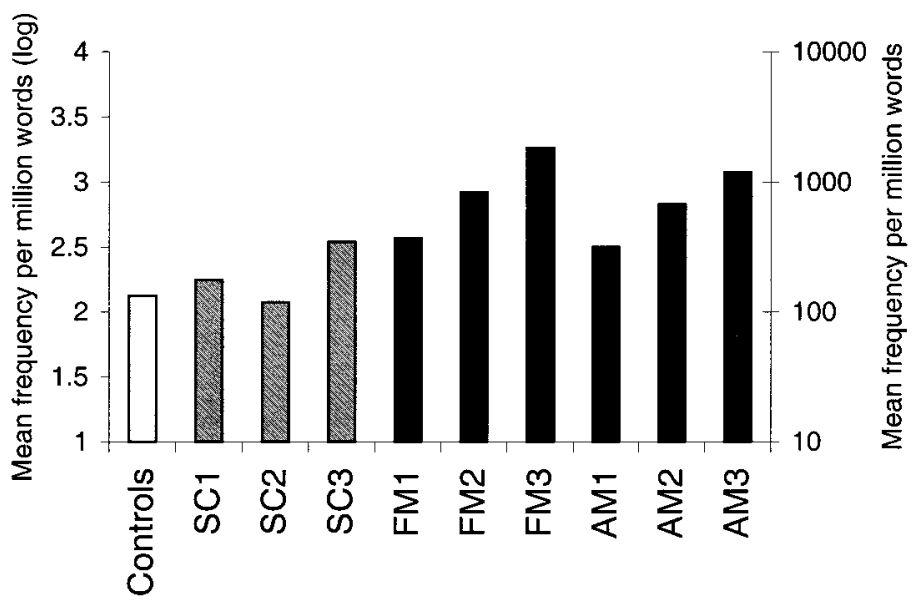

Subject and time period

FIG. 4. Mean frequency of nouns and verbs produced by control subjects and the three patients tested longitudinally.

ables $=$ class and time, random variable $=$ subject $)$. There was a main effect of class $F(1,5)=165.11, p<.001$, and of time $F(2,5)=6.16, p=.041$, but there were no interactions. These results indicate that the increase in mean word frequency as a function of progressing aphasia applies to all three patients irrespective of word class (and nouns were still of a lower mean frequency than verbs).

A one-way ANOVA comparing the SD subjects' nouns and verbs (combined) with those of normal controls in terms of word frequency was highly significant $F(9,987)=6.016, p<.001$. The individual patients' narratives which were significantly different from those of controls (according to Tukey's HSD) were the second and third for both FM ( $p=.009$ and $p=.012$, respectively) and AM ( $p=.021$ and $p<.001$, respectively). The distribution of frequency bands was averaged over the 20 normal control subjects and contrasted with each of the SD subjects' patterns of distribution. These can be seen graphically in Fig. 5. For FM and AM, not only did the "peak" (the modal frequency band) move progressively toward the higher frequency end, but words from the lower frequency bands eventually ceased to occur at all.

The consistency analysis in Table 5 shows that for FM and AM, the majority of the nouns and verbs from early narratives did not appear in later ones, and only a small number of high frequency items were retained throughout all narratives. SC still produced some low frequency items throughout, although the mean frequency for SC was higher in her third narrative. FM and AM used high frequency and general content words throughout. Although they both introduced new vocabulary in their third narratives, these items 

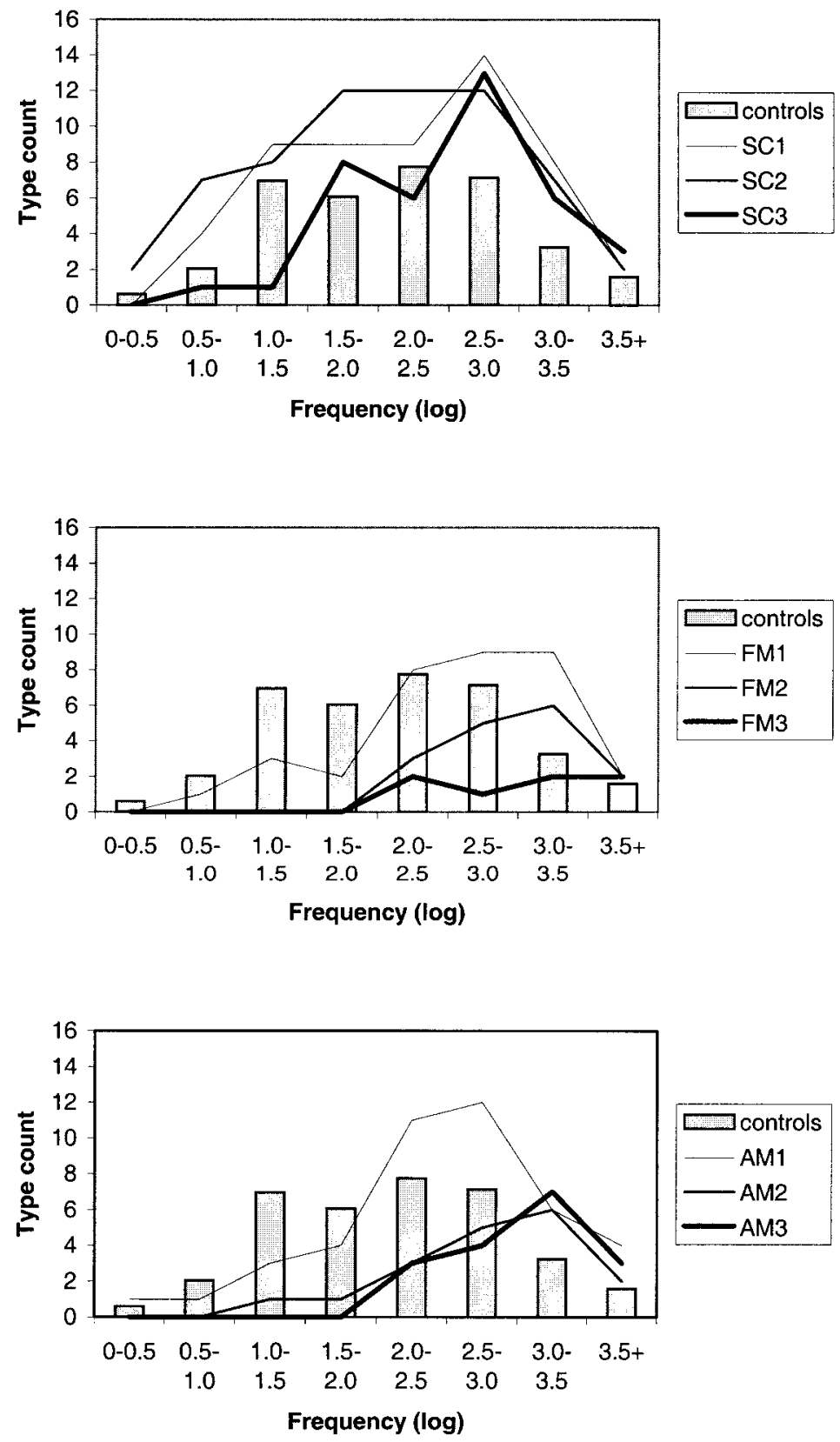

FIG. 5. Frequency distributions of nouns and verbs produced by each patient compared with normal control subjects. 


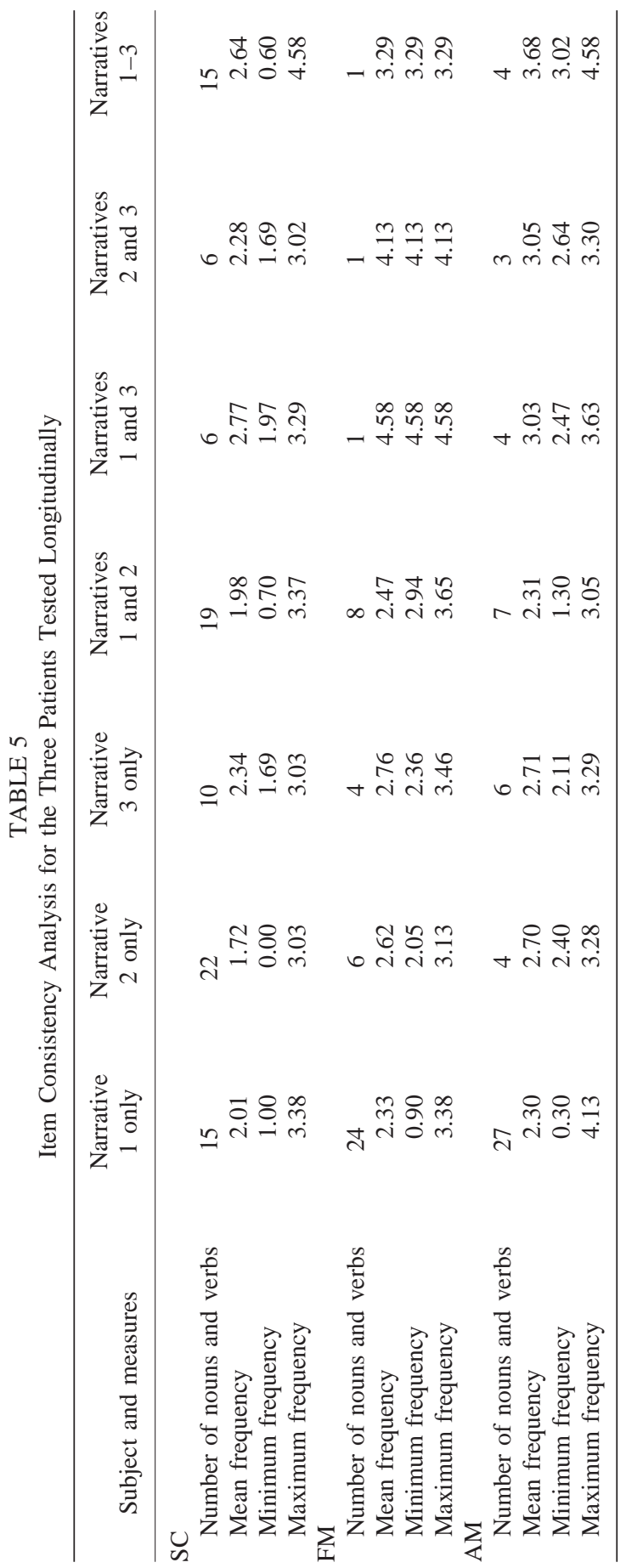


TABLE 6

Mean Imageability of Nouns and Verbs Produced by the Three Patients Tested Longitudinally

\begin{tabular}{lccc}
\hline $\begin{array}{l}\text { Subject and } \\
\text { time period }\end{array}$ & $\begin{array}{c}\text { Nouns and } \\
\text { verbs }\end{array}$ & Nouns & Verbs \\
\hline Controls & 510 & 569 & 414 \\
SC1 & 496 & 561 & 395 \\
SC2 & 509 & 545 & 413 \\
SC3 & 505 & 555 & 400 \\
FM1 & 476 & 581 & 378 \\
FM2 & 447 & 560 & 382 \\
FM3 & $337 *$ & 373 & 322 \\
AM1 & $443^{*}$ & 516 & 360 \\
AM2 & $411^{*}$ & 462 & 370 \\
AM3 & $386^{*}$ & 475 & 349 \\
\hline
\end{tabular}

* Indicates that the mean imageability of nouns and verbs collapsed is significantly lower than that of normal controls.

were very general: for FM they included a strategic phrase this special place for many objects that she could not name and for AM they reflected his tendency at this stage to proffer information not shown in the picture (she loves these two). SC showed much less impairment in retrieval of names of items in the picture; for example, she could say cookie and jar on all three occasions (although it should be noted that these words are written on the cookie jar in the picture stimulus). SC introduced new, less specific items including place and stuff only in narrative 3.

Table 6 shows the mean imageability ratings for nouns and verbs produced in each patient's testing session. Imageability ratings were entered into a univariate ANOVA (imageability = dependent variable, time and class = fixed variables, subject $=$ random variable), as had been conducted for the frequency analysis. This gave a significant main effect of class, $F(1,3)=$ $178.2, p<.001$ (verbs being lower imageability than nouns, as for the normal controls). No other main effects or interactions were shown. The nouns and verbs for the three patients were then combined and each compared with those of controls by a one-way ANOVA, which was highly significant, $F$ ( 9 , $893)=6.682, p<.001$. According to Tukey's HSD, in all three AM sessions and the third FM session the content words were characterized by significantly lower imageability ratings than those for normal controls. The complementarity of these results with those of the frequency analysis is no coincidence. There is a significant negative correlation $(r=-0.501, p<.001)$ between frequency and imageability: low imageability items tend to be more frequent. Consequently, as AM and FM produced fewer low frequency words, the mean imageability of their output decreased. 


\section{Discussion}

The longitudinal study has confirmed that the model picture descriptions presented in the first section provide a reasonable approximation to the patterns shown by real SD patients at various stages of severity. The models were prepared simply by removing lower frequency bands and substituting words of higher frequency, and their similarity to the speech of the SD patients strongly suggests that this is effectively what happens in progressive fluent aphasia. We predicted that the same process would produce an apparent specific word class deficit because verbs are relatively more frequent. We deduced from the model that there should be a significant reduction in the ratio of verbs to total narrative words only at the most severe stages of the progression: this is exactly what we found. The model picture descriptions also led to the hypothesis that the words produced at more impaired stages would be lower in imageability than those of normal controls, as another byproduct of the paucity of low frequency words. This prediction too was borne out by the patient data. The patients described above were at different stages in the progression of their aphasia, but by studying all three we begin to observe the outlines of a continuum. In the next section we aimed to fill some of the gaps in that continuum by adding further SD patients, each of whom had described the Cookie Theft and had also performed tests of single word production and comprehension on these testing sessions.

\section{CROSS-SECTIONAL STUDY}

\section{Subjects and Method}

In addition to the same three Cookie Theft narratives from each of the three patients described in the previous section, narratives collected from a further eight SD patients (in several cases, more than one) were analyzed in exactly the same manner. This gave a total of 21 narratives, and all but two patients had been assessed on the full range of assessments shown in Table 1.

For the purposes of this cross-sectional study, all 21 sets of data were treated as individual subjects. The subjects were divided into four groups reflecting different degrees of semantic impairment or "stages," based on their scores on the word-picture matching assessment; there was no overlap in these scores across the four stages. The mean scores and standard deviations on this comprehension test and other assessments for normal control subjects and the four stages are shown in Table 7. The results of these tests, as well as the ratios and mean frequencies of words produced in the Cookie Theft descriptions, were then compared across the four stages.

\section{Results}

A one-way ANOVA comparing the mean score at each stage for wordpicture matching was highly significant $(F(3,17)=212.1, p<.001)$, and 


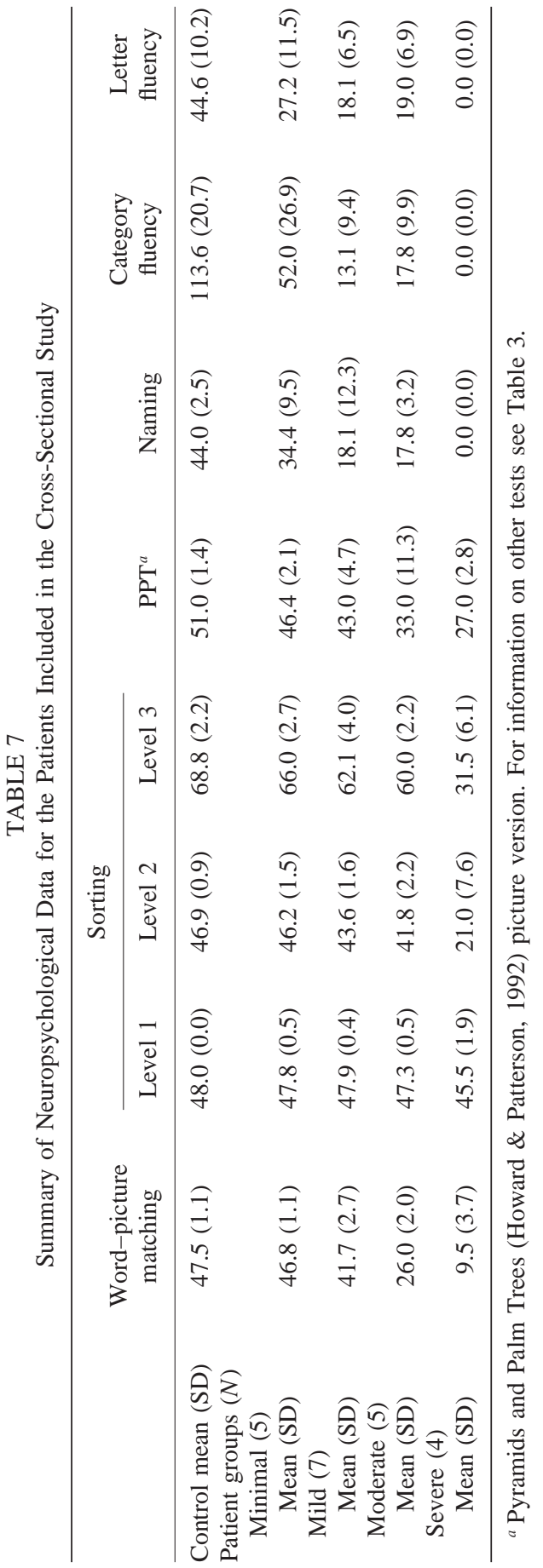




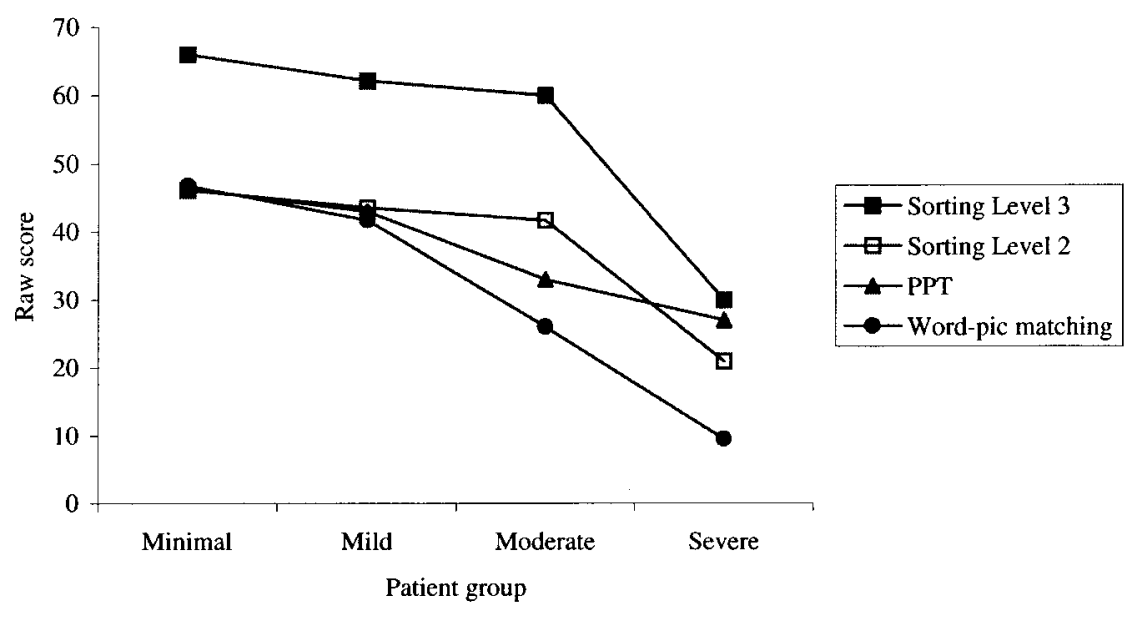

FIG. 6. Comprehension scores for the four stages included in the cross-sectional study. Footnote: The scores for sorting at level 3 are greater than for level 2 because the number of items is greater (max. $=72$ vs. 48 , respectively).

posthoc tests showed significant differences between all four stages. Figure 6 shows the mean scores on three other tests of comprehension in relation to that of word-picture matching, which was the basis for the grouping. Scores on both the sorting assessments and on the Pyramids and Palm Trees test (Howard \& Patterson 1992) declined across the four stages, consistent with the assignment based on word-picture matching. One-way ANOVAs on these assessments were all significant $(p<.001)$.

Figure 7 , which presents the mean raw scores across the four stages for

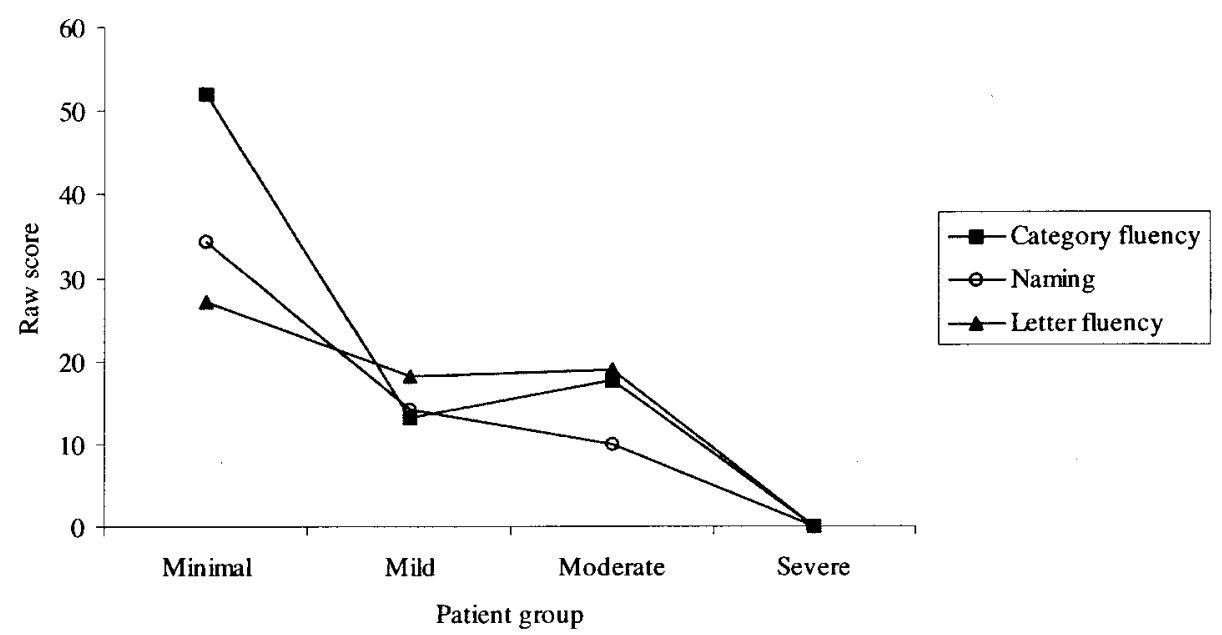

FIG. 7. Production scores for the four stages included in the cross-sectional study. 
tests of single word production, reveals a dramatic difference between the "minimal" stage and the more impaired subjects. The two fluency scores are not directly comparable: the raw scores for category fluency correspond to the number of items generated from a total of eight categories, but letter fluency scores represent the number of words produced for only three letters. One-way ANOVAs for the production tests were all significant [naming, $F(3,16)=11.8, p<.001$; category fluency, $F(3,17)=10.5, p<.001$; letter fluency, $F(3,15)=7.6, p=.003]$. Posthoc tests showed that the minimal stage scores for naming and category fluency were significantly higher than those for all other stages; for letter fluency tests, the scores for the severe stage were significantly lower than those for all other stages. These results suggest that naming and category fluency suffer a marked deterioration relatively early in the progression of the disease, but letter fluency and single word comprehension performance remain relatively stable until much later. In other words, as Gainotti, Silveri, Daniele, and Giustolisi (1995) observed, a mild semantic deficit can have a striking effect on confrontation naming and category fluency, while leaving comprehension (at least on these rather unchallenging assessments) as well as nonsemantically based word production relatively spared.

How then does increasing semantic impairment impact on the words used in the connected speech of these patients, as shown in picture description? One-way ANOVAs were performed on the ratios of nouns and verbs to total words for each stage. The noun ratio decreased significantly across the four stages $(F(3,17)=8.21, p=.001)$, and the pairwise differences were significant between the minimal and severe stages and between the moderate and severe stages; the difference in the verb ratio was not significant $(F<1)$.

The mean frequencies of the nouns and verbs produced by these subjects are shown in Fig. 8 and demonstrate the steady increase in frequency of items from both word classes across the four stages, significant by a oneway ANOVA (noun and verb frequencies collapsed), $F(3,641)=13.6, p<$ .001 ; all pairwise comparisons except that between mild and moderate were significant. This frequency analysis indicates both an early and continuing impact of semantic degradation on speech production: at the minimal stage words were produced with an average lower frequency than at all other stages, and at the severe stage words were produced with an average higher frequency than at all other stages. Analyzing the nouns and verbs separately yields similar results for both word classes [nouns, $F(3,348)=5.356, p=$ .001 , significant pairwise differences were between minimal and severe stages and between mild and severe stages; verbs, $F(3,289)=4.376, p=$ .005 , significant between minimal and severe stages only].

Figure 9 represents the content words produced at the four stages in the cross-sectional study, divided by the eight bands of frequency employed in 


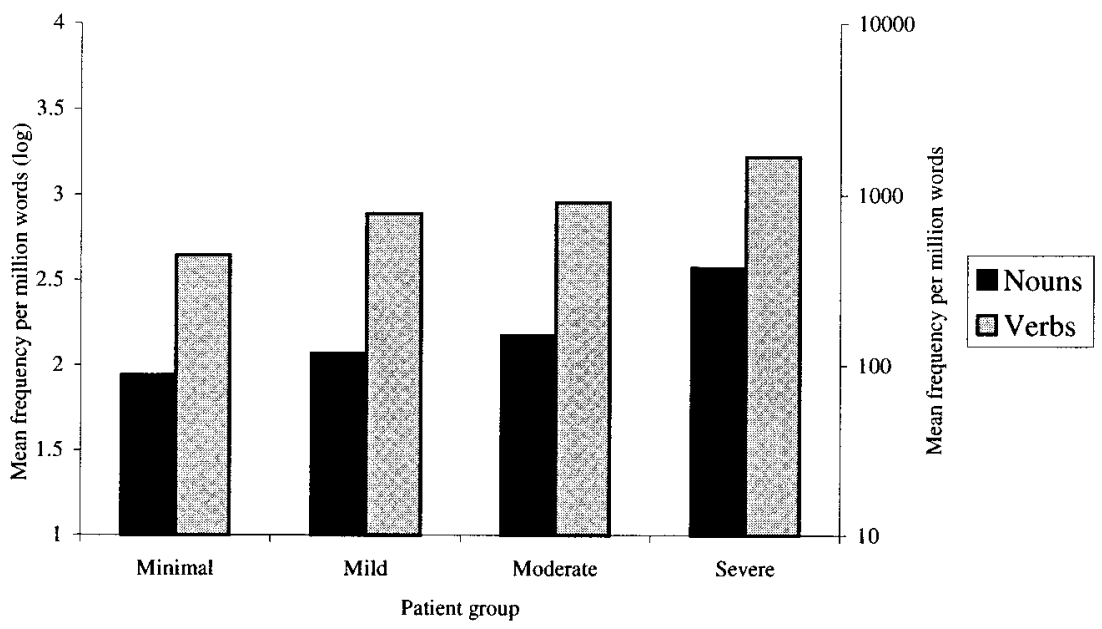

FIG. 8. Mean frequency of nouns and verbs produced at the four stages included in the cross-sectional study.

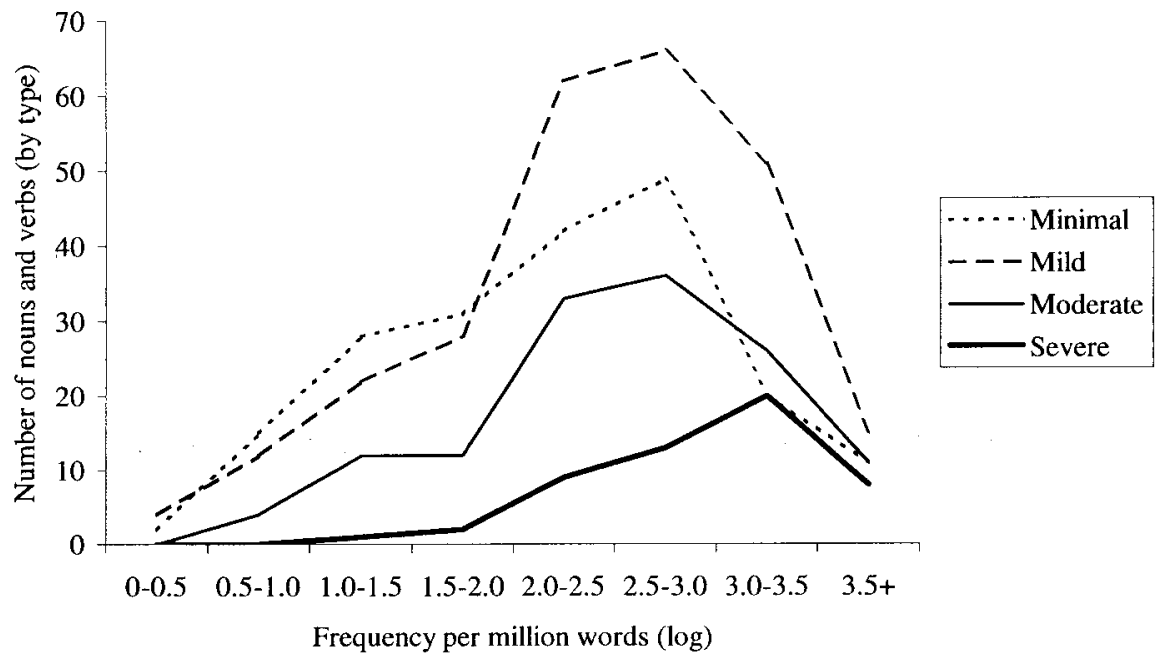

FIG. 9. Word frequency distributions for the four stages included in the cross-sectional study. 
the longitudinal study, and reveals a pattern very similar to that seen in Fig. 5 for the most severely impaired patients, FM and AM. Not only does the mean frequency of words generated increase with severity, but words in the lower bands of frequency progressively vanish.

\section{Discussion}

We have demonstrated that when individual test stages for SD patients are divided into groups on the basis of degree of semantic impairment (measured by word-picture matching), a marked decline can be seen in the vocabulary available in connected speech as well as in tests of single word comprehension and production. As semantic memory deteriorates over "time" (defined here cross-sectionally), the first single word measures affected are confrontation naming and category fluency. Even though patients in the early stages of progressive aphasia (the "minimal" stage) exhibit clear wordfinding problems in such tasks, the impairment is not immediately obvious in picture description, because many of the words normally recruited for this purpose can be replaced by other acceptable vocabulary. As the semantic impairment progresses, and more of the low frequency words become unavailable, the impact is revealed particularly in an analysis of the frequency bands occupied by the words produced in picture description ("mild" and "moderate" stages). It is only at the later stages, when comprehension is very severely impaired, that measures such as the ratio of nouns to total words in connected speech are significantly lowered. At this point the patients fail completely on all tests of single word production (naming and letter as well as category fluency). Although the number and variety of verbs (as well as nouns) available to the patients at the severe stage is obviously reduced, nevertheless the ratio of verbs to total words produced in the Cookie Theft description is largely unchanged across the four stages as a result of the continuing availability of very high frequency words which happen to be verbs, such as be, come, do, go, have, and think.

\section{GENERAL DISCUSSION}

We sought to characterize the impact of a progressive semantic impairment on a task requiring connected speech production, namely, the description of the Cookie Theft picture. In the Introduction we outlined methods of analysis that have been used by other researchers, noting the limitations of counts and ratios of word types for the identification of specific deficits; the importance of these caveats has been supported in our data. A more productive endeavor proved to be the examination of the individual words in terms of psycholinguistic variables, particularly word frequency. We focused on frequency because it has been shown to have a major effect on spoken word retrieval in semantic dementia and indeed in other nonpro- 
gressive aphasias (Ellis, Miller, \& Sin, 1983; Howard, Patterson, Franklin, Morton, \& Orchard-Lisle, 1984; Kay \& Ellis, 1987).

In order to test the premise that the least familiar concepts would suffer the greatest deterioration in a progressive semantic deficit, and consequently that the lowest frequency words would be the first to become unavailable, we modeled a series of Cookie Theft descriptions by simply replacing words in a low frequency range with higher frequency words and by successively raising this frequency threshold. The "normal" model was shown to be representative of narratives produced by normal subjects on a variety of measures including word type ratios and the distributions of frequency and imageability of the vocabulary used. The versions of this model restricted according to the frequency of the words available reflected the kinds of changes we observed in patients with moderate and severe semantic impairments. When the very low frequency words were substituted, we were forced to use more general terms, and an apparent word class deficit for nouns emerged. When only very high frequency items could be utilized, a reverse imageability effect also arose. That this series of created descriptions proved to be similar to real longitudinal data suggests that word frequency does, to a large extent, reflect the progressively restricted access to vocabulary in progressive fluent aphasia. Some variation is to be expected, as the frequency with which each (normal) individual encounters and produces a particular word varies; the Celex Database only constitutes an approximation of these personal frequency levels. Nevertheless, there was a striking similarity between the modeled versions with progressively fewer low frequency words and those of the patients with progressive semantic impairments.

The cross-sectional study demonstrated that when testing sessions from a larger set of patients with semantic dementia were divided into four groups according to the degree of semantic impairment, our measures from the Cookie Theft narratives also reflected the different levels of conceptual knowledge. A tightly constrained production task, such as picture naming, is the first to be affected by semantic impairment. The Cookie Theft picture description is less constrained, as precise vocabulary items can be replaced by alternative items; a mild semantic deficit might not, therefore, be obvious in connected speech without the type of analysis conducted here. When the semantic deficit becomes severe, the deficit is also revealed in ratios of word types. This is the stage at which comprehension tasks, such as sorting pictures of familiar objects on the basis of semantic categories /attributes, become severely affected. Depending on the nature and difficulty of the tests employed, mild damage to semantic memory is not always evident from comprehension assessments, suggesting that at least some cases of anomia with apparently spared comprehension may in fact be due to a mild semantic impairment (Lambon Ralph, McClelland, Patterson, \& Hodges, submitted for publication).

Word frequency was the only variable that we manipulated in the modeled 
Cookie Thefts, and yet this successfully predicted two important outcomes from the real patient data. When a patient can produce only the most frequently occurring vocabulary, the content words that are still available (a) comprise mainly verbs and very few nouns and (b) tend to be very general and therefore abstract. Marshall (1977, p. 144) commented on his own simulation of aphasic speech: "The most salient feature . . . is the inability to produce specific noun phrases. A few nouns . . . are uttered but certainly the deficit seems to be disproportionately severe for nouns."

The apparent deficits for nouns and for imageable/concrete words that result from a restriction to high frequency words have both been reported in the literature. Daniele et al. $(1993,1994)$ claimed that GP was worse at naming and understanding nouns than verbs. At the time when this effect was significant in their naming test, further neuropsychological assessment was not carried out. At the second testing period the patient was so poor at naming both nouns and verbs that the word class effect had disappeared, but the patient was more successful in lexical decision and word-picture matching with verbs than nouns. As we noted when discussing our methods of analyzing the Cookie Theft data, imageability is a rather neglected variable, particularly in studies manipulating word class. We have seen that most "pictureable" verbs are in fact rated as considerably less imageable than nouns. Imageability is closely correlated with concreteness, and Breedin et al. (1994) described a reverse concreteness effect (advantage for abstract words) in the patient DM, which the authors attributed to degraded knowledge of perceptual semantic features. It is conceivable that the "noun deficit" reported by Daniele et al. might also have been a consequence of differential impairment to perceptual attributes, as the nouns and verbs in their tests were controlled only for frequency and length.

Also consistent with this account is the fact that DM was significantly better at verbs in a verb/noun synonym triplets task but equally impaired at nouns and verbs in naming. Breedin et al. suggest that for such a severe semantic deficit, a naming test is not sensitive enough to show a word class difference. Degradation of perceptual features in semantic representations would render concrete nouns the most severely affected, while verbs and abstract nouns should be relatively spared. This was the pattern shown by DM, and perhaps this was also the reason for the apparent class effect in GP, the patient reported by Daniele and colleagues. These authors also described two patients, RA and GG, whose scans showed atrophy of the posterior regions of the left frontal lobes. Both were nonfluent (GG was described as consistent with a diagnosis of Progressive Supranuclear Palsy), and they performed more poorly with verbs. It is possible, if these patients had a general deficit for relatively abstract words, that verbs were adversely affected by virtue of their normally rather low imageability. The present study has highlighted the point that assertions regarding specific word class deficits should not be made without scrupulous control for other confounding factors. The kind of analysis that we have conducted on patients' picture descriptions 
is one method of illustrating how word class, frequency, and imageability interact, and it goes some way toward disambiguating these factors.

The cross-sectional study presented here has demonstrated that patterns of impaired speech production are closely linked to comprehension deficits across different levels of impairment, which is to be expected in a neuropsychological condition (semantic dementia) that is thought to represent a central degeneration of semantic memory. The important element here is that different degrees of semantic impairment yield quite different degrees of impairment in tasks of production and comprehension.

\section{APPENDIX}

\section{Model Cookie Theft (All Words Available)}

There are two children and their mother in the kitchen. The little boy has climbed up, on a three legged stool to get some cookies from the jar in the cupboard. The stool is about to fall over, so he's probably going to fall on the floor. His sister is holding up one hand as if she is waiting for him to pass her some of the cookies, and she's holding a finger to her mouth as if to warn her brother to be quiet. Meanwhile their mother is taking no notice. She's been doing the washing up and is now drying a plate. She has left the tap running and the sink is overflowing. There is a big puddle on the floor, and she's standing in it. She seems not to have noticed either the water or what her children are doing. She might be looking out of the window, which is open and looks out on the garden. You can see a path and another part of the house and the lawn, flowers, and a tree in the garden. It seems to be summer, as she is wearing a short sleeved dress under her apron. Her son is wearing shorts a shirt and shoes and socks, which are also falling down. Her daughter is wearing a short skirt and T-shirt. There are lots of cupboards all around the kitchen. There are two cups on the draining board.

\section{Model Cookie Theft_Bands of Log Frequency 1.0+ only (over 10 Occurrences per Million)}

There are two children and their mother in the kitchen. The little boy has climbed up, on a three legged stool to get some biscuits from the jar in the cupboard. The stool is about to fall over, so he's probably going to fall on the floor. His sister is holding up one hand as if she is waiting for him to pass her some of the biscuits, and she's holding a finger to her mouth as if to warn her brother to be quiet. Meanwhile their mother is taking no notice. She's been washing the dishes and is now drying a plate. She has left the tap running and the sink is overflowing. There is a lot of water on the floor, and she's standing in it. She seems not to have noticed either the water or what her children are doing. She might be looking out of the window, which is open and looks out on the garden. You can see a path and another part of the house and the lawn, flowers, and a tree in the garden. It seems to be summer, as she is wearing a short sleeved dress under her um I forget what you call it. Her son is wearing shorts a shirt and shoes and socks, which are also falling down. Her daughter is wearing a short skirt and top. There are lots of cupboards all around the kitchen. There are two cups on the board by the sink.

\section{Model Cookie Theft-Bands of Log Frequency 1.5+ only (over 32 Occurrences per Million)}

There are two children and their mother in the kitchen. The little boy has climbed up, on a um little chair to get something to eat from the erm up there. It's about to fall over, so 
he's probably going to fall on the floor. His sister is holding up one hand as if she is waiting for him to pass her some of them, and she's holding a finger to her mouth as if to warn her brother to be quiet. Meanwhile their mother is taking no notice. She's been washing up and is now drying a plate. She has left the um well left the water running and the water is going all over the floor. There is a lot of water on the floor, and she's standing in it. She seems not to have noticed either the water or what her children are doing. She might be looking out of the window, which is open and looks out on the garden. You can see a path and another part of the house and the erm grass, flowers, and a tree in the garden. It seems to be summer, as she is wearing a summer dress under her um I forget what you call it. Her son is wearing short erm I can't remember the word, a shirt and shoes and little oh um things on your feet, which are also falling down. Her daughter is wearing a short dress and top. There are lots of places to keep things all around the kitchen. There are two cups on the board by the lady who is drying up.

\section{Model Cookie Theft-Bands of Log Frequency 2.0+ only (over 100 Occurrences per Million)}

There are two children and their mother in the kitchen. The little boy has got up on a um little sort of chair to get something to eat from the erm up there. It's about to fall over, so he's probably going to fall on the floor. His sister is holding up one hand as if she is waiting for him to pass her some of them, and she's holding a oh erm finger to her mouth as if to tell her brother to be erm well not to let their mother hear. But their mother hasn't noticed. She's been doing jobs in the kitchen and well her mind is on other things. She has left the um well left the water running and the water is going all over the floor. There is a lot of water on the floor, and she's standing in it. She seems not to have noticed either the water or what her children are doing. She might be looking out of the window, which is open and looks out on the garden. You can see a road and another part of the house and the erm garden and a tree in the garden. It seems to be summer, as she is wearing a summer erm summer clothes under her um I forget what you call it. Her son is wearing short erm I can't remember the word, and on his feet he has erm I forget the name little oh um things on your feet, which are also falling down. Her daughter is wearing a short thing. There are lots of places to keep things all around the kitchen. There are two more things on the erm board by the lady who is working.

\section{Model Cookie Theft-Bands of Log Frequency 2.5+ only (over 317 Occurrences per Million)}

There are two children and their mother in the um in the room. The little boy has got up on a um a thing to get something from the erm up there. It's about to go over, so he's going to come down. There little girl is holding up one hand as if she is waiting for him to give her some of them, and she's holding a oh erm hand to her face as if to tell him to be erm well not to let their mother hear. But their mother hasn't seen them. She's been doing jobs in the kitchen and well her mind is on other things. She has left the um well left the water running and the water is going all over the place. There is a lot of water down there, and she's standing in it. She seems not to know about both the water and what her children are doing. She might be looking at something. You can see out to another part of the house and the erm things out there. She has got a um thing on under her um I forget what you call it. The little boy has got erm I can't remember the word, and on his feet he has erm I can't think of the name little oh um things on your feet, which are also coming down. The little girl has got a thing on. There are lots of places to keep things all over the room. There are two more things on the erm side by her where she is working. 


\section{Model Cookie Theft-Bands of Log Frequency 3.0+ only (over 1000 Occurrences per Million)}

There are two children there and she is over there. He has got up on a thing to get these from up there. It's about to go over, so he's going to come down. She looks as if she wants one too, she wants him to give one to her, and she's telling him not to erm well to make it that the other one won't know. But she hasn't seen them. She's doing other things and she's thinking of other things. She hasn't done the erm things there and it's all coming out down there. It's all gone down there and she's in it. She looks like she doesn't know about it and what her children are doing. She looks as if she is looking out there. You can see out there, and the things out there. She has got a um thing on over her um, oh it's gone. He's got um on his no they've gone, but they're coming down. She's got them as well. There are things all over to erm for things to be in. There are two more things on the um on there by the other one.

\section{REFERENCES}

Ardila, A., \& Rosselli, M. (1996). Spontaneous language production and aging: Sex and educational effects. International Journal of Neuroscience, 87, 71-78.

Baayen, R. H., Piepenbrock, R., \& van Rijn, H. (1993). The CELEX lexical database. Philadelphia, PA: Linguistics Data Consortium, Univ. of Pennsylvania. [CD-ROM]

Bastiaanse, R., \& Jonkers, R. (1998). Verb retrieval in action naming and spontaneous speech in agrammatic and anomic aphasia. Aphasiology, 12, 951-969.

Berndt, R. S., Haendiges, A. N., Mitchum, C. C., \& Sandson, J. (1997). Verb retrieval in aphasia: 2. Relationship to sentence processing. Brain and Language, 56, 107-137.

Bird, H., \& Franklin, S. (1996). Cinderella revisited: A comparison of fluent and non-fluent aphasic speech. Journal of Neurolinguistics, 9, 187-206.

Breedin, S. D., Saffran, E. M., Coslett, H. B. (1994). Reversal of the concreteness effect in a patient with semantic dementia. Cognitive Neuropsychology, 11, 617-660.

Breedin, S. D., Saffran, E. M., \& Schwartz, M. F. (1998). Semantic factors in verb retrieval: An effect of complexity. Brain and Language, 63, 1-31.

Cipolotti, L., \& Warrington, E. (1995). Semantic memory and reading abilities: A case report. Journal of the International Neuropsychological Society, 1, 104-110.

Croisile, B., Ska, B., Brabant, M. J., Duchene, A., Lepage, Y., Aimard, G., \& Trillet, M. (1996). Comparative study of oral and written picture description in patients with Alzheimer's disease. Brain and Language, 53, 1-19.

Daniele, A., Silveri, M. C., Giustolisi, L., \& Gainotti, G. (1993). Category-specific deficits for grammatical classes of words: Evidence for possible anatomical correlates. Italian Journal of Neurological Sciences, 14, 87-94.

Daniele, A., Giustolisi, L., Silveri, M. C., Colosimo, C., \& Gainotti, G. (1994). Evidence for a possible neuroanatomical basis for lexical processing of nouns and verbs. Neuropsychologia, 32, 1325-1341.

Ellis, A. W., Miller, D., \& Sin, G. (1983). Wernicke's aphasia and normal language processing: A case study in cognitive neuropsychology. Cognition, 15, 111-144.

Evans, J. J., Heggs, A. J., Antoun, N., \& Hodges, J. R. (1995). Progressive prosopagnosia associated with selective right temporal lobe atrophy: A new syndrome? Brain, 118, 113.

Gainotti, G., Silveri, M. C., Daniele, A., \& Giustolisi, L. (1995). Neuroanatomical correlates of category-specific semantic disorders: A critical survey. Memory, 3, 247-264. 
Giles, E., Patterson, K., \& Hodges, J. R. (1996). Performance on the Boston Cookie Theft picture description task in patients with early dementia of the Alzheimer's type: Missing information. Aphasiology, 10, 395-408.

Goodglass, H., \& Kaplan, E. (1983). The assessment of aphasia and related disorders. 2nd ed. Lea \& Febiger, Philadelphia.

Graham, K. S., \& Hodges, J. R. (1997). Differentiating the roles of the hippocampal complex and the neocortex in long-term memory storage: Evidence from the study of semantic dementia and Alzheimer's disease. Neuropsychology, 11, 77-89.

Graham, K. S., Lambon Ralph, M., \& Hodges, J. R. (1997a). Determining the impact of autobiographical experience on "meaning": New insights from investigating sports related vocabulary and knowledge in two cases with semantic dementia. Cognitive Neuropsychology, 14, 801-837.

Graham, K., Patterson, K., \& Hodges J. R. (1995). Progressive pure anomia: Insufficient activation of phonology by meaning. Neurocase, 1, 25-38.

Graham, N. L., Patterson, K., \& Hodges, J. R. (1997b). Progressive dysgraphia: Co-occurrence of central and peripheral impairments. Cognitive Neuropsychology, 14, 975-1005.

Hesketh, A., \& Bishop, D. V. M. (1996). Agrammatism and adaptation theory. Aphasiology, 10, 49-80.

Hodges, J. R., Graham, N., \& Patterson, K. (1995). Charting the progression in semantic dementia: Implications for the organisation of semantic memory. Memory, 3 463-495.

Hodges, J. R., \& Patterson, K. (1995). Is semantic memory consistently impaired early in the course of Alzheimer's disease? Neuroanatomical and diagnostic implications. Neuropsychologia, 33, 441-459.

Hodges, J. R., \& Patterson, K. (1996). Non-fluent progressive aphasia and semantic dementia: A comparative neuropsychological study. Journal of the International Neuropsychological Society, 2, 511-524.

Hodges, J. R., Patterson, K., Oxbury, S., \& Funnell, E. (1992). Semantic dementia: Progressive fluent aphasia with temporal lobe atrophy. Brain, 115, 1783-1806.

Howard, D., \& Patterson, K. (1992). The Pyramids and Palm Trees Test. Bury St. Edmonds: Thames Valley Test Co.

Howard, D., Patterson, K., Franklin, S., Morton, J., \& Orchard-Lisle, V. (1984). Variability and consistency in picture naming by aphasic patients. In E. Rose (Ed.), Advances in neurology, Vol. 42, Progress in aphasiology. New York: Raven Press. Pp. 263-276.

Jonkers, R., \& Bastiaanse, R. (1998). How selective are selective word class deficits? Two case studies of action and object naming. Aphasiology, 12, 245-256.

Kay, J., \& Ellis, A. W. (1987). A cognitive neuropsychological case study of anomia: Implications for psychological models of word retrieval. Brain, 110, 613-629.

Kitchener E. G., \& Hodges, J. R. (1999). Impaired knowledge of famous people and events with intact autobiographical memory in a case of progressive right temporal lobe degeneration: Implications for the organisation of remote memory. Cognitive Neuropsychology, 16, 589-607.

Knott, R., Patterson, K., \& Hodges, J. R. (1997). Lexical and semantic binding effects in short-term memory: Evidence from semantic dementia. Cognitive Neuropsychology, 14, 1165-1218.

Lambon Ralph, M. A., Graham, K. S., Ellis, A. W., \& Hodges, J. (1998). Naming in semantic dementia: What matters? Neuropsychologia, 36, 775-784.

Lambon Ralph, M. A., McClelland, J. L., Patterson, K. \& Hodges, J. R. No right to speak? The relationship between semantic impairment and anomia-Evidence from semantic dementia and a computational model. [submitted for publication] 
Marshall, J. C. (1977). Disorders in the expression of language. In J. Morton \& J. C. Marshall (Eds.), Psycholinguistics series, Vol. 1. London: Elek Science.

Marshall, J., Chiat, S., Robson, J., \& Pring, T. (1996). Calling a salad a federation: An investigation of semantic jargon. Part 2- Verbs. Journal of Neurolinguistics, 9, 251-260.

Marshall, J., Pring, T., \& Chiat, S. (1998). Verb retrieval and sentence production in aphasia. Brain and Language, 63, 159-183.

Medical Research Council. (1997). MRC Psycholinguistic Database. Oxford: Med. Res. Council.

Mendez, M. F., \& Ashlamendez, M. (1991). Differences between multi-infarct dementia and Alzheimer's disease on unstructured neuropsychological tasks. Journal of Clinical and Experimental Psychology, 13, 923-932.

Miceli, G., Laudanna, A., \& Burani, C. (1991). Batteria per l'analisi dei deficit afasici. Milan: Associazione per le ricerche neuropsicologiche.

Mummery, C. J., Patterson, K., Wise, R. J. S., Price, C. J., \& Hodges, J. R. (1999). Disrupted temporal lobe connections in semantic dementia. Brain, 122(1), 61-73.

Rochon, E., Saffran, E. M., Berndt, R. S., \& Schwartz, M. F. (1998). Quantitative production analysis: Norming and reliability data. Brain and Language, 65, 10-13.

Saffran, E. M., Berndt, R. S., \& Schwartz, M. F. (1989). A quantitative analysis of agrammatic production: procedure and data. Brain and Language, 37, 440-479.

Snowden, J. S., Goulding, P. J., \& Neary, D. (1989). Semantic dementia: A form of circumscribed cerebral atrophy. Behavioural Neurology, 2, 167-182.

Tomoeda, C. K., Bayles, K. A., Trosset, M. W., Azuma, T., \& McGeagh, A. (1996). Crosssectional analysis of Alzheimer disease effects on oral discourse in a picture description task. Alzheimer's Disease and Associated Disorders, 10, 204-215.

Tyler, L. K., Moss, H. E., Patterson, K., \& Hodges, J. R. (1997). The gradual deterioration of syntax and semantics in a patient with progressive aphasia. Brain and Language, 56, $426-476$.

Tyler, L. K., \& Moss, H. E. (1998). Going, going, gone . . . ? Implicit and explicit tests of conceptual knowledge in a longitudinal study of semantic dementia. Neuropsychologia, 36, 1313-1323.

Warrington, E. K. (1975). The selective impairment of semantic memory. Quarterly Journal of Experimental Psychology, 27, 635-657.

Zingeser, L. B., \& Berndt, R. S. (1990). Retrieval of nouns and verbs in agrammatism and anomia. Brain and Language, 39, 14-32. 